\title{
A QUESTIONNAIRE BASED STUDY TO EVALUATE PERFORMANCE OF A CME PROGRAMME BY THE PARTICIPANTS
}

M. M. Jain, Minakshi Kokate, Shantibhushan Kamble, Ramanand Patil

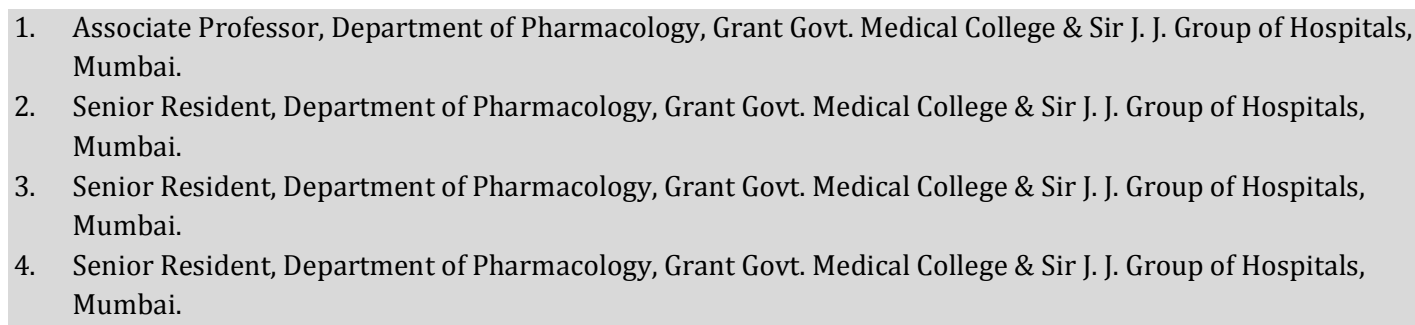

\section{CORRESPONDING AUTHOR}

Dr. M. M. Jain,

Associate Professor of Pharmacology, Grant Govt. Medical College \& Sir J J Group of Hospitals, Mumbai - 400008.

E-mail: mangalmjain@gmail.com

Ph: 00919920066441

ABSTRACT: INTRODUCTION: Performance evaluation of any learning - teaching activity by the students is routine exercise at most of the international institutions for higher education. Some speakers prefer to evaluate their own skills by giving pre-designed set of questions to the prospective participants for their own record and further improvement. Here, we have tried to evaluate overall performance of a CME programme as conceived by the participants. The reasons for doing so were many folds. Firstly, the topic of CME was out of context to medical curriculum and it was sensitive too. Secondly, there were no incentives for the participants to attend the programme other than CME theme i.e. no MMC credit hours, no gifts, no food but only a certificate of participation. Lastly, during the planning of CME programme, doubts were expressed by some of the college authorities as regard to success of CME. All these prompted us to seek first hand information from the participants regarding their views on CME topic, speakers and academic content. MATERIAL \& METHODS: This was a questionnaire based evaluation. All three resident doctors under the guidance of CME faculty prepared a set of questions to evaluate CME performance in respect of the topic, the speakers and overall assessment of entire activity. The questions were prepared accordingly and pilot tested in some volunteers. Each question had five options ranging from strongly agreed to strongly disagree. Result was expressed in term of percentage response in either 'agree' or 'disagree category'.

RESULTS: The response of participants to CME activity was unexpectedly overwhelming. Almost, 85 to $95 \%$ of participants liked the topic. All the speakers were highly appreciated for their presentation and knowledge. Nearly $95 \%$ of the participants opined favourably to overall success of CME. CONCLUSIONS: From the results, it can be concluded that there was overwhelming response from the participants to this CME activity. More such CMEs may be planned in future without fear of any controversy.

KEY WORDS: Feedback questionnaire Evaluation of a CME activity faculty performance evaluation Assessment of CME 
INTRODUCTION: Department of Pharmacology, Grant Govt. Medical College \& Sir JJ Group of Hospitals in collaboration with Brahmakumari's Global hospital, Mumbai, organized a CME programme titled "spiritual strategy and its values in healthcare" on 14th January 2013 at GGMC and JJH. The selection of CME topic was based on the response to a KAP study undertaken by us at our own institute to check Knowledge, Attitude and Practices among medical professionals regarding role of spirituality in management of health and diseases(1). Profound interest shown by the participants to this KAP study motivated us to arrange for an elaborate CME programme on spiritual medicine wherein the faculty for the CME included medical professionals with additional expertise in spiritual preaching and practices. Accordingly, we invited Dr Ashok Mehta from Brahmakumari's Global Hospital, an internationally renowned onco-surgeon who conducts VIHASA programme for medical professionals all over the country along with Dr Sachin Parab, a renowned social activist as our faculties for the CME. The in-house team of speakers included Dr M M Jain who had actively participated as faculty in national and international conferences on spirituality as well as Dr D V Kaundinya, Ex Professor and Head of microbiology and a Brahmakumari's devotee (Appendix 1). All the speakers have been working in the field of spiritual medicine as evident by their contributions in national and international journals $(1,2,3)$. After getting formal approval for the proposed CME programme by the institutional authorities, there was a moment of set-back. The hospital authorities became suspicious about the success of CME as the theme appeared to be out of context to medical curriculum. They anticipated some serious controversies that may arise during deliberations because of the nature of CME theme. However, the faculty assured the concern authorities of no such possibilities as the role of spiritual intervention in health management is well recognized world over and there is nothing objectionable in the content or presentation by the speakers. Nevertheless, the speakers thought it appropriate to obtain feedback from the participants for their own record and for the future genesis of this unexplored topic of immense medical importance.

MATERIAL AND METHODS: We followed standard pattern for evaluation of teaching performance used most commonly (4).The resident doctors in the department of pharmacology, Dr Minakshi Kokate, Dr Shantibhushan Kamble and Dr Ramanand Patil took the initiative in this regard. They prepared a set of questions under the guidance of faculty for the CME. Initially, the questions were pilot tested among 8 volunteers who constituted representative group of prospective participants at CME. The questions were framed to evaluate CME programme mainly from three perspectives: 1) "The topic", 2) "The speakers" and 3) "Overall assessment". Each question was assigned five options viz Strongly agreed, Agreed, Neutral, Disagreed and Strongly Disagreed. The participants were asked to select one option which is most appropriate to relevant question according to them. The questionnaire was distributed among the participants before start of CME activity. Disclosing the name of the responder was made mandatory to ascertain credibility of data thus obtained. The feedback forms were collected back at the conclusion of CME activity. The response was reviewed and analysis was done.

ANALYSIS: For the sake of convenience, the five options for each question were resolved in to two categories viz. (Strongly agreed- Agreed) or (Neutral- Disagreed-Strongly Disagreed). The results were expressed as percentage response in each of two categories from the total as $100 \%$. 
RESULTS: There were a total of 70 registrations for the CME programme. Majority of the participants were present at the start of the CME but some had to leave in between to attend their hospital duties. In all, we received 45 completed feedback forms from the participants which were then analysed and the result is presented below in the tabular form (Table-1).

DISCUSSION: Performance evaluation of any learning-teaching activity is always desirable but seldom done. From among many CMEs at our institute, to our knowledge, none was evaluated from participants' point of view. Probably, we would also have followed the same trend, but due to initial controversy which cropped up during developmental phase of CME that prompted us to get first hand information from the participants and their views regarding such activities in future.

The unique features about this CME were

$>$ Subject topic was out of prescribed medical curriculum

$>$ Exclusively for Doctors ranging from PG students to senior most professors and Head of Departments

$>$ Open for all religious groups irrespective of caste, creed, faith or belief.

$>$ No MMC credit points were assigned which was communicated to all the prospective participants well in advance.

$>$ No registration fees, No gifts to participants, No lunch/Dinner but only certificate of participation.

$>$ No Mementos for faculty.

The above features indicate that participants attended the CME programme out of their interest and enthusiasm in the subject rather than any other non-academic incentive. The faculty participation was purely for dissemination of information about evidenced based spiritual benefits in health management.

From the results, it is amply clear that participants wholeheartedly supported the CME activity. Regarding the topic, the response in favour of it ranged from 70 to $98 \%$. About speakers, the favourable response ranged from 81 to $100 \%$ and CME overall success was rated as 87 to $98 \%$. Interestingly, $77 \%$ of the participants clearly mentioned that they do not attend CMEs for MMC credit hours. The overwhelming response from the participants which constituted heterogeneous population of different religion, different faith, different cadre, different class, from both the genders but one common characteristic that all of them belonged to medical profession, indicated that CME programme was unanimously accepted and appreciated by all. The fact that the CME was organized at one of the premiere institutions in the country having tertiary care facilities in all specialties and the participants included some of the most senior clinicians, the overwhelming response is testimony to CME success. Nonetheless, the initial concern of institutional authorities for the CME success cannot be underestimated as any misgivings by the speakers, directly or indirectly, may tarnish institute's image and drag the people into unnecessary controversies as evident from a recently published report in one of the leading news papers ${ }^{(5)}$. Interestingly, the entire CME activity was termed as non-controversial, unbiased, truly scientific and enriching by all the participants. Indeed, the scientific contours, the Speakers experience and the participant's wisdom made the CME activity - a memorable event. 
CONCLUSIONS: From the results, it can be concluded that there was overwhelming response from the participants to this CME activity. More such CMEs may be planned in future without fear of any controversy.

ACKNOWLEDGMENT: We are thankful to Padmashree Dr T P Lahane, Dean, Grant Govt. Medical College \& Sir JJ Group of Hospitals for the permission to hold CME at this institution and his cautious remarks regarding the topic. We also thank Dr S B Patel for his support to CME in its planning and execution. Our special thanks are due to Dr D V Kaundinya who was instrumental in convincing the authorities for need of such CMEs. Lastly, we are thankful to all the delegates who attended the event in great majority with zeal and enthusiasm.

\section{REFERENCES:}

1. Dr.M.M. Jain, Dr Abhijeet Joshi, Mr Nikhil G.Tayade, Dr. S.R. Jaiswar, Dr. Karan B. Thakkar; Knowledge, Attitude and Practices regarding "the role of Spirituality in Current Medical Practice amongst Medical Professionals" in a tertiary care Hospital. JEMDS (2013);2;3;p204-225

2. M M Jain; Ahimsak Chikitsa ; Souvenir: Better Ideas for Better Tomorrow : IV JDICON 2008; Mumbai.

3. M M Jain; Animal ingredients in medicines; Souvenir: Modern Medicine \& Science with Spirituality for Global Health \& Peace; VII JDICON 2011, Pune.

4. Evaluation of lecturer teaching performance, UNE, The University of New England; 2006, SAMP 101.

5. Akhtar, Ilaiah spar over religion: Times of India, $26^{\text {th }}$ January 2013 edition.

Table-1: Percentage response of participants to feedback questions in each category

\begin{tabular}{|l|l|l|l|}
\hline \multirow{2}{*}{$\begin{array}{l}\text { Q } \\
\text { No. }\end{array}$} & Questions & \multicolumn{2}{l|}{ Response (\%), n=45(100\%) } \\
\cline { 3 - 4 } & & $\begin{array}{l}\text { Strongly Agreed } \\
\text { / Agreed }\end{array}$ & $\begin{array}{l}\text { Strongly Disagreed } \\
\text { Disagreed } \\
\text { Neutral }\end{array}$ \\
\hline About the Topic: & 11 \\
\hline 1 & $\begin{array}{l}\text { I was made aware about the aims and objectives of } \\
\text { the CME theme }\end{array}$ & 89 & 30 \\
\hline 2 & $\begin{array}{l}\text { The brief write-up in the circular supported the } \\
\text { CME objectives }\end{array}$ & 70 & 12 \\
\hline 3 & $\begin{array}{l}\text { The sequence of presentation helped me } \\
\text { understand the subject }\end{array}$ & 88 & 03 \\
\hline 4 & The academic contents of lectures was stimulating & 97 & 02 \\
\hline 5 & The CME topic is need of the hour & 98 & 14 \\
\hline 6 & $\begin{array}{l}\text { The subject material of the CME was related to } \\
\text { medical practice }\end{array}$ & 86 & 05 \\
\hline 7 & The entire activity was well organised & 95 & 14 \\
\hline 8 & The topic generated a great deal of enthusiasm & 86 & \\
\hline About the Speakers: & & \\
\hline
\end{tabular}




\begin{tabular}{|c|c|c|c|}
\hline 9 & $\begin{array}{l}\text { The presenter seems to have good knowledge } \\
\text { about the subject }\end{array}$ & 100 & 0 \\
\hline 10 & The subject material was presented at right pace & 93 & 7 \\
\hline 11 & $\begin{array}{l}\text { The subject material was free of jargon (useless } \\
\text { stuff) }\end{array}$ & 91 & 9 \\
\hline 12 & The speakers explained the subject clearly & 100 & 0 \\
\hline 13 & $\begin{array}{l}\text { Speakers created enthusiasm and interest among } \\
\text { the participants }\end{array}$ & 88 & 12 \\
\hline 14 & $\begin{array}{l}\text { Speakers encouraged questioning from the } \\
\text { participants }\end{array}$ & 86 & 14 \\
\hline 15 & $\begin{array}{l}\text { Speakers attended all the queries and answered } \\
\text { these satisfactorily }\end{array}$ & 81 & 19 \\
\hline \multicolumn{4}{|c|}{ Overall assessment of CME } \\
\hline 16 & Overall activity was enriching & 98 & 02 \\
\hline 17 & The CME improved my understanding of the topic & 95 & 05 \\
\hline 18 & $\begin{array}{l}\text { It improved my ability to utilize skills related to } \\
\text { topic }\end{array}$ & 93 & 07 \\
\hline 19 & I would recommend such CMEs to others & 93 & 07 \\
\hline 20 & $\begin{array}{l}\text { I would attend other CME programme } \\
\text { organised by this team }\end{array}$ & 93 & 07 \\
\hline 21 & $\begin{array}{l}\text { My main objective to attend the CME is to secure } \\
\text { MMC credit points }\end{array}$ & 23 & 77 \\
\hline 22 & The topic was appropriate for target audience & 87 & 13 \\
\hline 23 & The presentations were lively and energetic & 93 & 07 \\
\hline 24 & Ppt slides were clear and tangible & 95 & 05 \\
\hline 25 & $\begin{array}{l}\text { The CME has positive impact on my thought } \\
\text { process }\end{array}$ & 93 & 07 \\
\hline
\end{tabular}

\section{Appendix 1: Detailed CME programme}

\begin{tabular}{|l|l|l|}
\hline Time & Topics & Speakers \\
\hline 1:30 to 2:00 & High Tea & \\
\hline $2: 30-3: 00$ & $\begin{array}{l}\text { Inauguration, Introduction, Projection of CME } \\
\text { theme }\end{array}$ & $\begin{array}{l}\text { Dr T P Lahane } \\
\text { Dr S B Patel } \\
\text { interventions }\end{array}$ \\
\hline $3: 00-3: 15$ & Incurable means whose cure lies within & Dr M M Jain \\
\hline $3: 15-5: 15$ & VIHASA: Value In Healthcare-A Spiritual Approach & $\begin{array}{l}\text { Dr Ashok Mehta \& } \\
\text { Dr Sachin Parab }\end{array}$ \\
\hline $5: 15-5: 45$ & Question hour and interactive session & $\begin{array}{l}\text { All the participants } \\
\text { \& Speakers }\end{array}$ \\
\hline $5: 45-6: 00$ & Participant's feedback and vote of thanks & $\begin{array}{l}\text { Dr } \\
\text { Kokate }\end{array}$ \\
\hline
\end{tabular}

